\title{
Radiosonde stratospheric temperatures at Dumont d'Urville (Antarctica): trends and link with polar stratospheric clouds
}

\author{
C. David ${ }^{1, *}$, P. Keckhut ${ }^{1}$, A. Armetta ${ }^{1}$, J. Jumelet ${ }^{1}$, M. Snels ${ }^{2}$, M. Marchand ${ }^{1}$, and S. Bekki ${ }^{1}$ \\ ${ }^{1}$ LATMOS-IPSL, UVSQ, Univ. UPMC Paris 6, Paris, France \\ ${ }^{2}$ ISAC-CNR, Rome, Italy \\ *also at: Institut Polaire Français Paul-Emile Victor (IPEV), Plouzané, France
}

Received: 27 October 2009 - Published in Atmos. Chem. Phys. Discuss.: 1 December 2009

Revised: 1 April 2010 - Accepted: 9 April 2010 - Published: 23 April 2010

\begin{abstract}
Temperature profiles measurements are performed daily (00:00 UT) in Dumont d'Urville $\left(66^{\circ} 40^{\prime} \mathrm{S}, 140^{\circ} 01^{\prime} \mathrm{E}\right)$ by Météo-France, using standard radiosondes, since the International Geophysical Year in 1957. Yet, due to a 16 years data gap between 1963 and 1978, the entire dataset is only used for a qualitative overview. Only the most recent series, between 1979 and 2008, is used to investigate the interannual stratospheric temperatures variability. Over Dumont d'Urville, at the edge of the vortex, the annual mean temperature cooling of about $1 \mathrm{~K} / \mathrm{decade}$ at $20 \mathrm{~km}$ is the result of the cooling trends between 0.5 and $1.4 \mathrm{~K} /$ decade, in summer and autumn and a warming of about $1.1 \mathrm{~K} /$ decade in spring. These values are consistent with values obtained using data from inner vortex stations, but with smaller amplitude. No statistically significant trend is detected in winter. We propose here the first attempt to link stratospheric temperature trends to Polar Stratospheric Cloud (PSC) trends in Antarctica based on the only continuous 20 years database of PSC lidar detection. Despite the absence of mean temperature trend during winter, the occurrence of temperatures below the NAT threshold between 1989 and 2008 reveals a significant trend of about $+6 \% /$ decade. The PSCs occurrences frequency exhibits a concomitant trend of about $+3 \% /$ decade, although not statistically significant. Yet, this is consistent with results obtained in the Northern Hemisphere. Such a possible positive trend in PSC occurrence has to be further explored to be confirmed or invalidated. If confirmed, this PSC trend is likely to have strong impacts, both on ozone recovery and climate evolution in Antarctica. The study also reveals the importance of trends on extreme temperatures, and not only on mean temperatures.
\end{abstract}

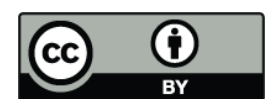

Correspondence to: C. David (christine.david@latmos.ipsl.fr)

\section{Introduction}

The evolution of stratospheric temperatures has been recognized to be an essential component of the stratospheric ozone changes (WMO, 2007), in particular because most of the ozone linked reaction rates are temperature dependent. In turn, stratospheric ozone depletion contributes to temperature changes. Stratospheric temperatures are also a reliable indicator of climate change (IPCC, 2007).

The secular increase in greenhouse gases (GHG) concentrations is correlated with a global well known warming at the Earth surface (IPCC, 2007). A cooling trend is observed in the stratosphere (Beig et al., 2003; WMO, 2007), with a magnitude larger than the warming at the surface by one order of magnitude (Rind et al., 1990). The lower stratosphere cooling reaches a globally averaged $\sim 0.3$ to $0.5 \mathrm{~K} /$ decade since 1979 (Ramaswamy et al., 2001; Randel et al., 2009) and can thus be used as an early "fingerprint" for atmospheric changes. The stratospheric cooling is partly a radiative response to GHGs concentrations increase, modulated by solar cycles and volcanic aerosols loading (Shine et al., 2003; Cordero and de Foster, 2006; Dameris et al., 2005; Austin et al., 2009; Thompson and Solomon, 2005, 2009; WMO, 2007 and references therein). Meanwhile, attribution studies indicate that the long term cooling in global-mean lower stratospheric temperatures is largely driven by changes in stratospheric ozone (Rosier and Shine, 2000; Ramaswamy and Schwarzkopf, 2002; Langematz et al., 2003; Shine et al., 2003; Ramaswamy et al., 2006). The stratospheric cooling could thus slow down as ozone recovers, with a rate depending on the magnitude of increase in the GHGs concentrations.

Globally, the most pronounced cooling is observed in the upper stratosphere near $40-50 \mathrm{~km}$. In latitude, the largest cooling trends are observed in the Antarctic lower stratosphere, during spring and summer, in association with the development of the Antarctic ozone hole (Ramaswamy et al., 2001; Randel et al., 2009). In the meantime, increase

Published by Copernicus Publications on behalf of the European Geosciences Union. 
of GHGs tends to speed up the Brewer-Dobson circulation (e.g., Butchart et al., 2006; Li et al., 2008), which, in turn, may impact on the vertical and latitudinal characteristics of the ozone recovery distribution (Shepherd, 2008; Li et al., 2009). An acceleration of the Brewer-Dobson circulation is expected to bring more ozone-poor air into the tropical lower stratosphere and more ozone-rich air into the mid and high latitudes (Jiang et al., 2007, Li et al., 2009). Ozone recovery should thus be faster in these regions and attenuate the stratospheric cooling faster there than in the tropics. Chemistry-climate model simulations (Li et al., 2009) indicate a strong inter-hemispheric difference, with less poleward transport into the Southern Hemisphere than into the Northern Hemisphere. Meanwhile, despite some indirect observational support (Thompson and Solomon, 2005, 2009), doubts remain on the model-simulated strengthening of the BrewerDobson circulation (Engel et al., 2009).

The interplay between temperature, transport and ozone appears to be particularly complex in Antarctica. An example of complex interactions is the feedback between stratospheric temperatures changes and Polar Stratospheric Cloud (PSC) formation. PSCs trigger the ozone hole by activating chlorine during the winter polar stratosphere (Peter, 1997; Solomon, 1999; Lowe and MacKenzie, 2007 and references therein). Stratospheric cooling or warming should impact their occurrence. Yet, PSC formation is a threshold process that does not depend only on mean temperatures but also on the frequency of cold episodes with temperature dropping below a given limit.

The coupling between radiation, dynamics, and chemistry make it difficult to analyse independently the causal links between changes in stratospheric composition and temperature trends. Indeed, models that have progressively acquired the capability to perform more realistic simulations of the stratosphere by including improved interactive chemistry schemes, exhibit large biases at high latitudes, especially in the Southern Hemisphere (Austin et al., 2009). Reliable polar temperature series are then crucial for the independent detection and attribution of atmospheric temperature changes in polar regions as well as for model evaluation (WMO, 2007; Austin et al., 2009). However, long-term temperature series are scarce in Antarctica. They constitute a significant scientific input for the assessment of the Intergovernmental Panel on Climate Change (IPCC) (2007) and a valuable reference, as the uncertainties in satellites observations and meteorological analyses are the strongest at high latitudes.

Here we present temperature series derived from the meteorological daily radiosondes at the French Antarctic station Dumont d'Urville (hereafter DDU) that have never been studied independently before. And we correlate the evolution of stratospheric temperatures to the lidar detection of PSCs. The main objective is to analyse in detail the links between temperature variations (mean and extremes) and PSC occurrence over a 20 year period. Previous temperature trend studies including DDU data used temperature series since 1979 on a coarse vertical resolution (meteorological characteristic altitudes from the Integrated Global Radiosonde ArchiveIGRA) (Thompson and Solomon, 2005). As the analysis of PSCs requires highly resolved temperature profiles, we consider here temperature data at a higher vertical resolution. Also, the basic temperature overview takes into account data dating from 1957. The plan of the paper is as follow: first, in Sect. 2, the data are described, then cross-checked in Sect. 3. Inter-annual variability and trends are derived in Sect. 4 . Section 5 focuses on an attempt to link, in a simple way, low temperature occurrences with PSC frequency as observed by lidar since 1989. We discuss the results and conclude in Sect. 6.

\section{Data description}

Daily meteorological Pressure-Temperature-hUmidity (PTU) radiosoundings (Meteo-PTU) are made at the French Antarctic station Dumont d'Urville by the French Meteorological Institute (Météo-France) since 1957. These meteorological profile observations are carried out within an intergovernmental agreement coordinated by WMO in order to insure an optimum horizontal sampling in this region where observational coverage is poor. Measurements are performed daily at 00:00 UT using balloon borne standard meteorological sensors, including pressure, temperature and humidity detection. Data are transmitted in real time to the ground station.

Meteo-PTU soundings with the original vertical resolution are available only for two distinct periods, separated by several years of interruption: 1957-1962 and 1979-2008. For the two periods, sensors and balloon types are described in Table 1. Three major changes are to be noticed. In 1986, Mesural instrumentations were substituted by Vaisala sondes. In 2002, Vaisala RS80 were replaced with improved Vaisala RS90 sensors, and since 2007, MODEM sondes are used. The maximum reached altitude depends on the balloon type and on the preliminary preparation, as well as on the encountered air temperatures. It has slightly changed along the series. Meanwhile, most of the soundings reach at least the altitude of $20 \mathrm{~km}(\approx 50 \mathrm{hPa})$. This level represents the lower stratosphere well and is roughly the median altitude of the PSCs formation range (David et al., 1998; Santacesaria et al., 2001).

In order to get an overview of the database, we explore the temperature evolution throughout the 1957-2008 period. Figure 1 shows the evolution of the monthly averaged temperatures at $20 \mathrm{~km}$ for every month with color codes to distinguish between the seasons, from 1957 to 2008. Temperature drops by about $11.3 \mathrm{~K}$ over 50 years, that is, a cooling, obtained with a linear fit, of about $2.3 \mathrm{~K} /$ decade between 1957 and 2008. The lowest variability is observed in summer, which is the dynamically most stable period of the year. Surprisingly, the variability appears to be lower in spring than in 
Table 1. Types of sondes and balloons used for temperature soundings at Dumont d'Urville between 1957 and 1962 and since 1979.

\begin{tabular}{lll}
\hline Time Period & Temperature sensors & Balloon type \\
\hline January 1957-December 1962 & MESURAL FMO 1955 & Darex 925 \\
November 1979-March 1986 & MESURAL FMO 1955 & Delasson 127DC \\
April 1986-October 1997 & VAISALA RS80/NE & Delasson 122DC \\
November 1997-October 2002 & VAISALA RS80-15G & Totex 500g \\
November 2002-October 2005 & VAISALA RS90-AG & Cosmoprene KKS \\
November 2005 - today & MODEM M2K2-DC & Totex 300g \\
\hline
\end{tabular}

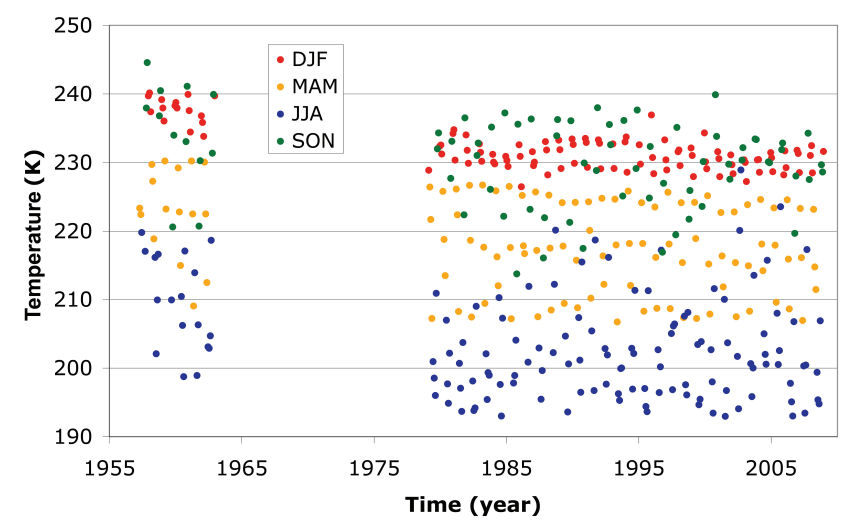

Fig. 1. Monthly averaged temperatures at $20 \mathrm{~km}$ for every month (with color codes to distinguish between the seasons) between 1957 and 2008 as derived from daily radiosondes at Dumont d'Urville.

winter, whereas the dynamical variability is expected to be higher in spring.

The vertical profiles of mean temperature differences between 1979-2008 and 1957-1962 are represented in Fig. 2, for each of the four seasons. The error bars are one-sigma standard deviations of the data around the mean values. The mean differences are significant above $10 \mathrm{~km}$ (roughly the polar tropopause). The most significant and biggest differences are observed in summer and winter, though the uncertainties are larger in winter, as expected from the natural geophysical variability. The differences exhibit a maximum of almost $15 \mathrm{~K}$ around $25 \mathrm{~km}$ in summer and spring and range between 5 and $10 \mathrm{~K}$ at $20 \mathrm{~km}$. Due to the gap of 16 years between the two periods 1957-1962 and 1979-2008, these values are only indicative estimates of a mean difference, even if they lay in the range of Antarctica trend values obtained in other studies (Randel et al., 2009; Thompson and Solomon, 2002). Despite their qualitative aspect, they support the significant stratospheric cooling, clearly demonstrated elsewhere (IPCC, 2007 and references therein, Randel et al., 2009), that occurred in the lower polar stratosphere within the last 50 years, even at the edge of the Antarctic continent.
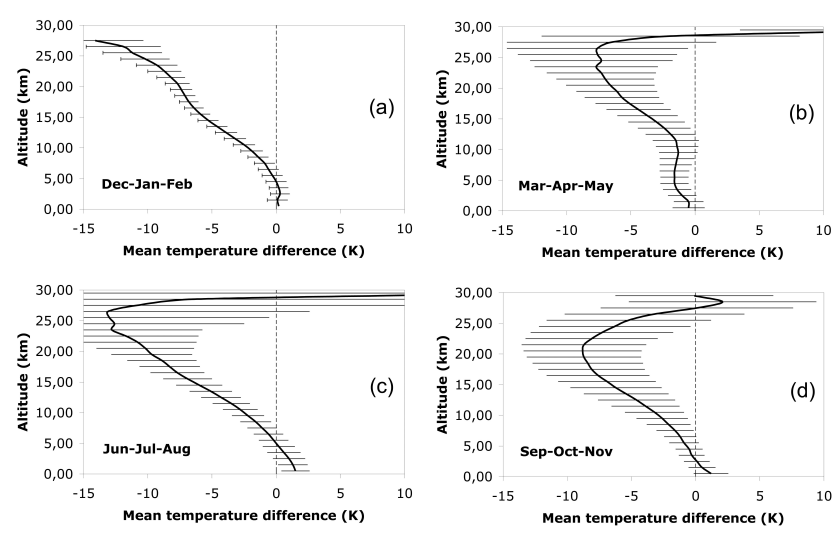

Fig. 2. Mean seasonal temperature profiles differences between the 1979-2008 and the 1957-1962 periods over Dumont d'Urville, for (a) summer, (b) autumn, (c) winter and (d) spring. One-sigma standard deviations are shown.

Indeed, as the temperature monitoring has evolved with time, in particular with instrumental changes and temporal sampling, the use of two time periods separated by 16 years for trend analysis is certainly questionable. The series continuity of the Meteo-PTU was investigated using a multiregression function that includes step functions to simulate instrumental bias between two sampling periods (Keckhut et al., 1999). Despite the instrumental changes, according to the statistical analysis, no significant bias appeared within the 1979-2008 period. This regression analysis has been proved to be efficient when gaps are limited to one or two years, but the results were shown to be unreliable for gaps larger than a decade. In order to avoid misinterpretations, in section 4, we will thus focus the trend analysis on the 1979-2008 period.

\section{Data validation}

More recently, since 1992, PTU measurements are made together with ozone soundings (O3-PTU), but with a lower frequency than the daily Meteo-PTU. About 30 O3-PTU soundings per year are performed, with the higher launch frequency during austral summer. These observations are conducted in the framework of the Network for the Detection of 

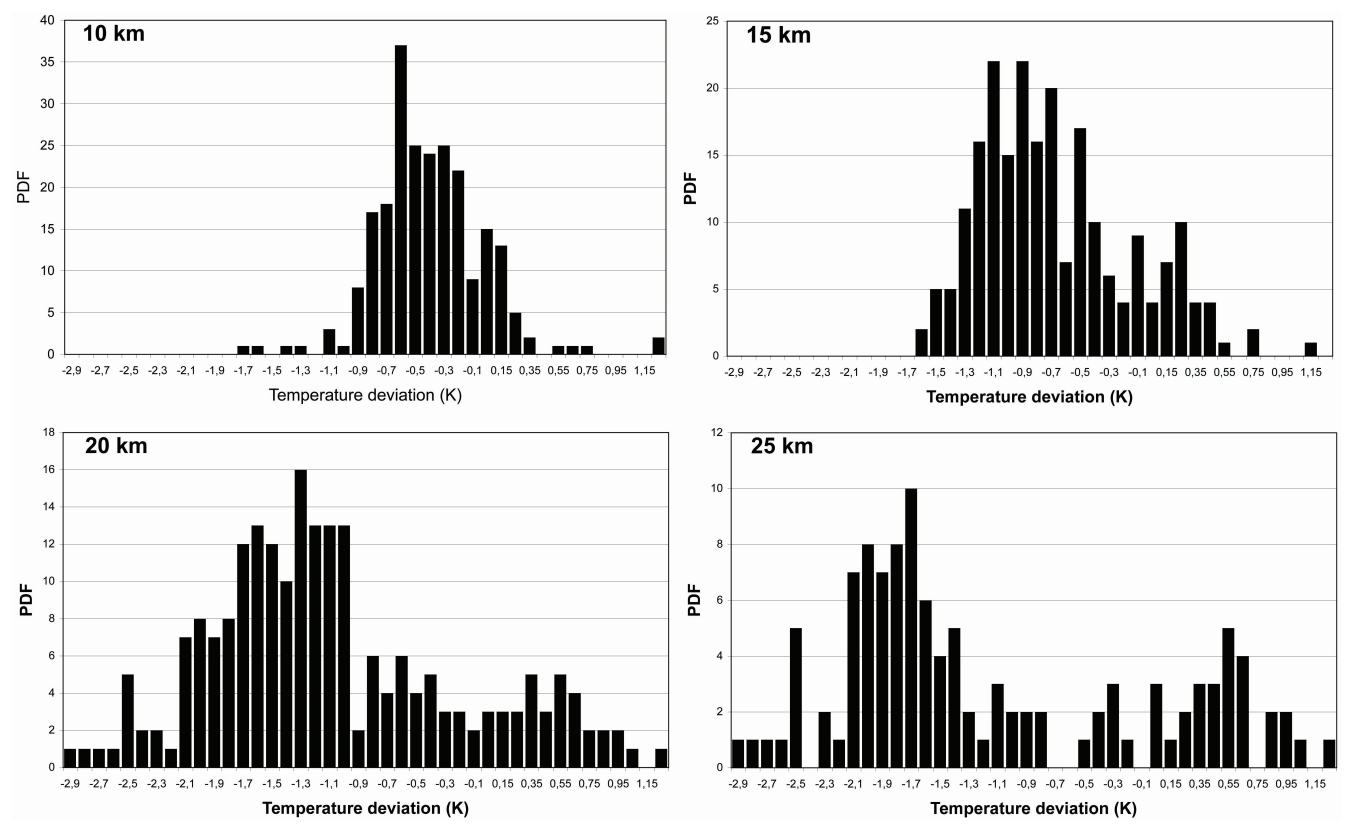

Fig. 3. Anomaly distributions between O3-PTU and Meteo-PTU measured temperatures every $5 \mathrm{~km}$ from 10 to $25 \mathrm{~km}$.

the Atmospheric Composition Changes (NDACC, previously NDSC) (Kurylo and Solomon, 1990) under the responsibility of the Institute Pierre-Simon Laplace (IPSL). Ozone is measured using electrochemical cells which are interfaced with standard meteorological sondes similar to the daily MeteoPTU and use the same detection rack than Meteo-PTU. The simultaneous acquisition of ozone and meteorological parameters profiles enables deduction of the altitude and allows deriving ozone density and mixing ratio. The sensors and acquisition systems for Meteo-PTU and O3-PTU are similar, but are operated independently with different set-ups.

When temperature measurements were carried out with Meteo-PTU and with O3-PTU within less than $60 \mathrm{~min}$, temperature data from both observations was compared. 248 coincidences were obtained but only 121 reached simultaneously the altitude of $25 \mathrm{~km}$. Balloons used for ozone sounding are bigger $(1500 \mathrm{~g}$ as compared to $500 \mathrm{~g}$ or $300 \mathrm{~g})$ than those used for Meteo-PTU, and they are handled with a specific coating to give them a better resistance to cold temperatures. They are thus able to reach higher altitude levels.

Figure 3 displays the anomaly distributions between O3PTU and Meteo-PTU measured temperatures every $5 \mathrm{~km}$ from 10 to $25 \mathrm{~km}$. A difference of few tens of degrees is observed at $10 \mathrm{~km}$ and reaches about $2 \mathrm{~K}$ in average at $25 \mathrm{~km}$. The anomaly distribution shows a somewhat bimodal structure at most levels. The existence of larger biases in the lower stratosphere was already reported (Parker et al., 1997; Gaffen et al., 2000). The potential causes of this observed relative discrepancy can be related to biases induced by extremely cold temperatures found in the vicinity of the tropopause and above, to biases in the altitude estimates deduced from pressure measurements or to small scale geophysical disturbances like gravity waves. As meteorological sondes and operators are the same, the discrepancy can also be due to the size of the balloons (Tiefenau et al., 1989) or to the analysis software (e.g. sensor linearity correction). However, from these features, we can get an idea of the sensitivity limit of temperature measurements ranging from roughly $0.3 \mathrm{~K}$ to $2 \mathrm{~K}$ with increasing altitude.

\section{Temperature inter-annual variability and trend estimates}

From the Meteo-PTU series collected by Météo-France in DDU, temperature trends analyses were performed for the 1979-2008 period with a least square fit of a multi-regression model called "AMOUNTS" (Adaptative MOdel for UNambiguous Trend Survey). The AMOUNTS model has already been described in detail (Hauchecorne et al., 1991; Keckhut et al, 1995). It includes sinusoidal functions to fit the seasonal changes, a linear trend calculation, a term linearly related to the solar activity given by the $10.7 \mathrm{~cm}$ solar radio flux, and a term associated with stratospheric aerosol content (data updated from Sato et al., 1993). The regression function, versus time $(t)$ and altitude $(z)$, can be expressed by:

$$
\begin{aligned}
& T(t, z)=a_{0}(z)+a_{1}(z) \cdot \cos \left[\frac{2 \pi t}{365}+\varphi_{1}(z)\right] \\
& +a_{2}(z) \cdot \cos \left[\frac{2 \pi t}{183}+\varphi_{2}(z)\right]+b(z) \cdot t+c(z) \cdot \operatorname{solar}(t) \\
& +d(z) \cdot \tau(t)+\operatorname{residual}(t, z)
\end{aligned}
$$

where $a_{0}(z)$ corresponds to the mean; $a_{1}(\mathrm{z})$ and $a_{2}(\mathrm{z})$ are the amplitudes of the annual and semi-annual seasonal changes; 
$\varphi_{1}(\mathrm{z})$ and $\varphi_{2}(z)$ correspond to the time of the maximum for both cosine functions; $b(z)$ is the searched trend and $c(z)$ is the solar atmospheric response amplitude to solar forcing [solar $(t)] ; d(z)$ is the response to large optical depth $[\tau(t)]$ following major volcanic eruptions. The residual $(\mathrm{t}, \mathrm{z})$ corresponds to the difference between measurements and the fitting model.

For the present analyses, the Quasi Biennial Oscillation (QBO) term was tested. It is found not to be significant and do not affect the magnitude of the trend estimates. Consequently, the QBO term is not considered into the final regressions in this case. The multi-regression analysis also reveals that the atmospheric solar signal is very small and not significant. Despite this small derived solar response, this term is kept in the analysis of the trend estimates to ensure that it does not induce any spurious trend effect.

Calculations of the trend uncertainties and of the other regression coefficients are based on the residuals. For this reason, the uncertainty is strongly dependent on the season. Owing to the correlation between two successive measurements (through their dependence on geophysical processes), the uncertainties for each term derived from the analysis are computed taking into account an autocorrelation function. In the present work, temperature profiles are derived from daily observations and are degraded into monthly mean profiles per altitude level. Following Tiao et al. (1990), with such a sampling, the autocorrelation of the residuals should be low. The trend uncertainties are derived while considering the autocorrelation coefficients, according to the appendix in Logan (1994).

One of the most significant factors influencing temperature trends, especially in the lower stratosphere, is the aerosol content, when enhanced following a volcanic eruption. Two potential effects are at play: the direct temperature response to aerosol heating and an induced dynamical impact (WMO, 1995 and references therein). In the stratosphere, volcanic aerosols scatter the solar radiation back to space, cooling the Earth's surface and, to a lesser extent, they absorb infrared radiation, warming the stratospheric levels where particles reside (Hansen et al., 1992; Robock, 2000). Major volcanic eruptions thus result in a warming in the stratosphere, particularly in the tropical and subtropical regions, but also, with smaller amplitude, at higher latitudes (Labitzke and McCormick, 1992). Then, temperature changes induce a dynamical effect with additional wave energy propagation into the stratosphere at lower mid-latitudes, producing, in the end, low latitude cooling and high latitude warming (Rind et al., 1992). Within the 1979-2008 period, El Chichon eruption in March-April 1982 injected $\sim 7 \mathrm{Tg}$ of $\mathrm{SO}_{2}$ into the stratosphere, Mount Pinatubo in June $1991 \sim 20$ Tg and the CerroHudson in August $1991 \sim 3 \mathrm{Tg}$ (ASAP, 2006). Most of the volcanic clouds were located in the $15-25 \mathrm{~km}$ altitude range and were slowly advected toward the poles to finally exhibit a global coverage after about 1 or 2 years (ASAP, 2006 and reference therein). When trend estimates are derived, a large

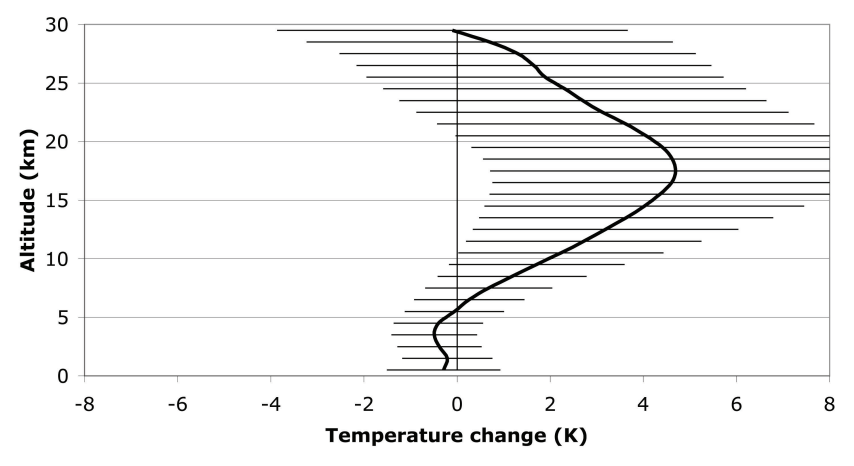

Fig. 4. Vertical profile of the spring (Sep-Oct-Nov) mean amplitude of the atmospheric temperature response to volcanic aerosols as estimated by AMOUNTS from the Dumont d'Urville radiosondes database between 1979 and 2008. One-sigma uncertainty estimations are shown.

temperature deviation is associated with the eruptions (variable " $d$ " in Eq. 1), according to the large aerosol loading during the 2-3 years following the eruption. The atmospheric response to volcanic eruptions is estimated using the multiregression analysis. Figure 4 focuses on the spring mean amplitude profile of this response as the variability for the three other season is too large to infer statistically significant results. As expected, cooling is observed near the surface and a warming of nearly $2 \mathrm{~K}$ in the $15-20 \mathrm{~km}$ range is detected. These temperature trends due to volcanic aerosols are comparable to results from previous observational and modeling studies (Labitzke and McCormick, 1992, Robock, 2000; Robock et al, 2007). The volcanic aerosols stratospheric heating is taken into account in the following regression analysis.

Step functions can be included in AMOUNTS to model potential sudden changes in the series possibly induced by instrumental modifications. Two parameters are related to the step-functions: the date of the change and the amplitude of the step, together with the associated uncertainty. The discontinuities in meteorological data series have been already tested (Gaffen et al., 2000), but the attribution of the change cause, instrumental or geophysical, is always controversial. In the method used here, described in Keckhut et al. (1999), such instrumental discontinuities are evaluated together with large scale geophysical fluctuations. Yet, the robustness of the method is complex to address as it depends on the shortterm natural variability and on the interdependence of the different forcing terms (Kerzenmacher et al., 2006). No specific sensitivity studies have been yet performed, but the statistical significance of the discontinuities amplitude can be tested with this method. Here we consider that a discontinuity can be expected if the amplitude of the change is larger than the one-sigma standard deviation. This is the case for the entire series between 1957 and 2008 but not for the 1979-2008 period. 

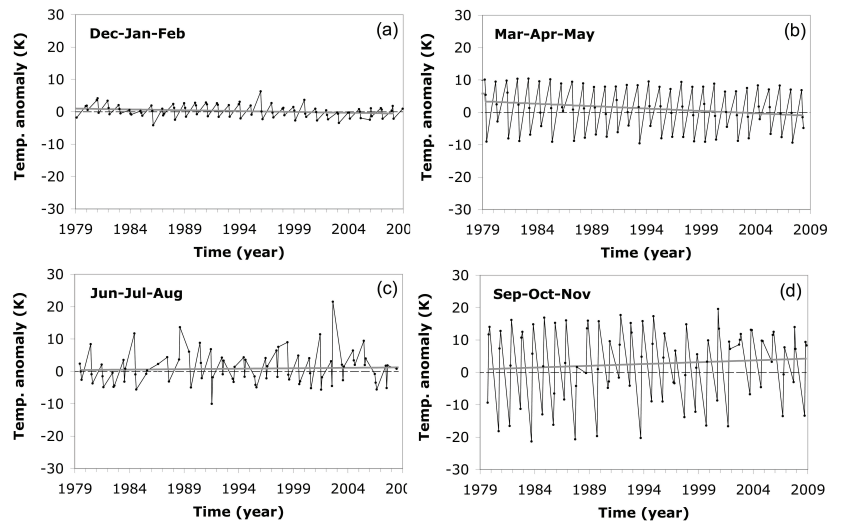

Fig. 5. Mean temperature anomalies at $20 \mathrm{~km}$ at Dumont d'Urville between 1979 and 2008 for the three corresponding months in (a) summer, (b) autumn, (c) winter and (d) spring (one point for each month of a season, that is, three points per season). The "zero" lines are dashed and the grey lines are the estimated trend.
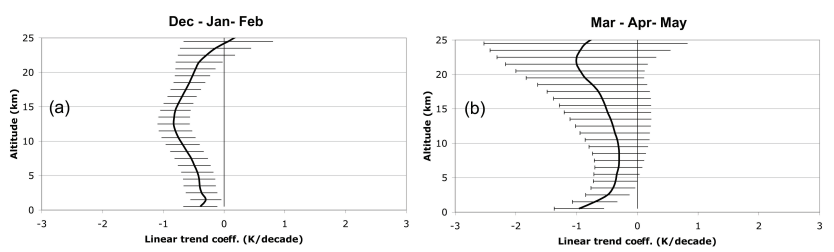

Jun - Jul - Aug
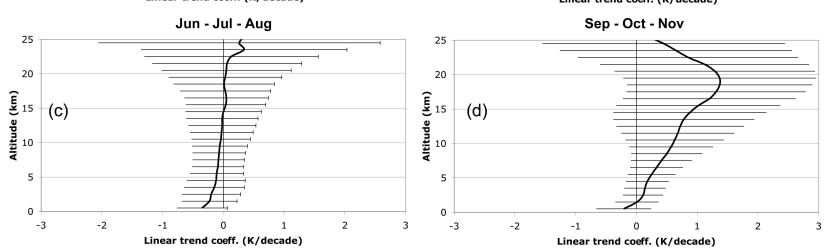

Fig. 6. Seasonal linear trends profiles at Dumont d'Urville, as derived from the AMOUNTS model by averaging the three corresponding monthly mean temperatures for (a) summer, (b) autumn, (c) winter and (d) spring. One-sigma uncertainty estimations are shown.

The annual-mean temperature anomalies do not exhibit significant trends, probably because the different seasonal trends present opposite signs. The annual trend estimate is calculated with the AMOUNTS model, providing a maximum at $23 \mathrm{~km}$ of $-1.1 \pm 2.4 \mathrm{~K} / \mathrm{dec}$. Monthly trends (variable " $b$ " in Eq. 1) were estimated with the AMOUNTS model. Figure 5 displays the mean temperature anomalies at $20 \mathrm{~km}$ for each season by averaging the three corresponding monthly mean temperatures, with one point for each month of a season (that is, three points per season). Austral summer and autumn trends (Dec-Jan-Feb and Mar-Apr-May) show significant coolings of respectively -0.5 and $-1.4 \mathrm{~K} /$ decade. The negative trend in autumn seems higher than in summer, but the autumn variability is stronger. During winter a slight warming trend of $0.27 \mathrm{~K} / \mathrm{dec}$ ade is observed. But the exceptional major sudden warming of August 2002 (Newman et al., 2005; Simmons et al., 2005; Stolarski et al., 2005) tends to distort the trend estimate. Without considering the 2002 data points, no statistically significant trend is detected in winter. Surprisingly, a positive trend of $1.1 \mathrm{~K} /$ decade is seen in spring. It is worth pointing out that the radiosondes do not sample the same air masses above DDU in winter and in spring. DDU is on the edge of the polar vortex. During winter, the station is located outside of the vortex only in less than $5 \%$ of the cases, whereas during spring, it is outside the vortex between 20 and $60 \%$, depending on the altitude (Godin et al., 2001). The very large variability in spring temperatures is then partly related to the difference of temperature between air masses sampled within or at the edge of the vortex and air masses from outside of the vortex. From the ECMWF potential vorticity (PV) analyses at $520 \mathrm{~K}$ $(\sim 20 \mathrm{~km})$, the position of DDU relatively to the vortex edge can be estimated. When measurements performed within/at the edge of the vortex and outside the vortex are treated separately, the data samples are becoming too small to derive statistically significant results.

Figure 6 shows the seasonal linear trends profiles, up to $25 \mathrm{~km}$. The number of radiosondes reaching altitude above this level is too low to consider the seasonal temperature means as reliable. Here again, no significant trend, at any altitude level, can be seen during winter. A positive trend is detected in spring, with a maximum just below $20 \mathrm{~km}$, corresponding to the period when temperatures are sampled partly within or on the edge of the vortex and partly outside. This spring warming has to be related to the dynamical feedback associated with the vortex breakdown (Waugh et al., 1999). The stratospheric trends over DDU are significantly negative during summer and autumn.

Daily radiosondes in Dumont d'Urville indicate positive trend at $20 \mathrm{~km}(\sim 50 \mathrm{hPa}$ or $520 \mathrm{~K})$, in winter and spring, but are not statistically significant, while a statistically significant cooling trend is detected in summer and autumn. These results for a single location are in good agreement with previous studies from Randel and Wu (1999) and Thompson and Solomon (2002), both reporting a significant warming during early spring and a cooling during late spring and summer at the continent scale. In polar regions, the cooling due to GHG radiative forcing is expected to be less than $-1 \mathrm{~K}$ in the lower stratosphere (Shindell et al., 2004), while the radiative forcing due to ozone, computed with a fixed dynamical heating model, leads to a cooling of about $-1.4 \mathrm{~K} /$ decade around $18-20 \mathrm{~km}$ (Foster and Shine, 1997; Shine, 2003), which is in good agreement with our findings in autumn. On the vertical, the observed trends at DDU in summer and autumn are in excellent agreement with the trends profiles derived by Randel et al. (2009) from radiosondes datasets from three Antarctic stations at Syowa $\left(69^{\circ} \mathrm{S}\right)$, McMurdo $\left(78^{\circ} \mathrm{S}\right)$ and South Pole/Amundsen-Scott $\left(90^{\circ} \mathrm{S}\right)$. Even if these bases are located poleward in the continent relatively to DDU position, deep in the polar vortex, DDU is also always located within the vortex in winter. In addition, during this season, winds, PV and 


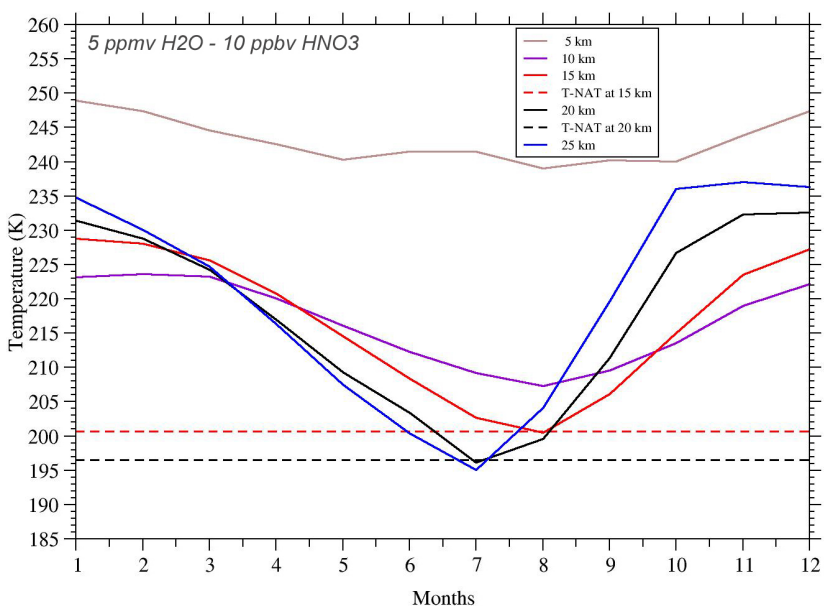

Fig. 7. Mean annual cycle in temperature for different altitude levels $(5,10,15,20$ and $25 \mathrm{~km})$ for the 1979-2008 period at Dumont d'Urville; NAT threshold temperatures are shown for 5 ppmv $\mathrm{H}_{2} \mathrm{O}$ and 10 ppbv $\mathrm{HNO}_{3}$ vapor contents at 15 and $20 \mathrm{~km}$ (dashed lines).

temperature fields are usually overlapping in the Antarctic lower stratosphere (WMO, 1995). Thus, the similarity between the vertical profiles of the winter temperature trends for the vortex edge station (DDU) and for the inner vortex stations (Syowa, McMurdo and South Pole) is not surprising. It reflects the evolution of the temperature within the Antarctic vortex as a whole, although with smaller cooling at the edge of the vortex. In autumn, when the vortex is just forming, air masses inside and outside are expected to be at somewhat similar temperatures. This explains the similarity of vertical trends over DDU and deeper in the Antarctic (Syowa, McMurdo and South Pole) during this season. In winter, no trend is detected over DDU, while a slight warming is reported for the inner vortex stations between 10 and $20 \mathrm{~km}$ by Randel et al. (2009). In spring, the position relative to the vortex has a strong influence on the vertical temperature trends behavior. In this season, the temperature differences between inside and outside the vortex are well established. During this season, the position of DDU with respect to the vortex fluctuates very significantly, resulting in a sampling of inside and outside vortex regions. The trends at DDU in spring are opposite to those found in the inner vortex by Randel et al. (2009). This is likely to reflect both the sampling inside and outside the vortex at DDU and the earlier vortex breakdown at the edge region.

\section{Temperature seasonal variability and PSC formation}

\subsection{Temperature evolution}

Figure 7 shows the mean annual cycle in temperatures at Dumont d'Urville for different altitude levels from 5 to $25 \mathrm{~km}$, for the 1979-2008 period. The amplitude of the annual cycle
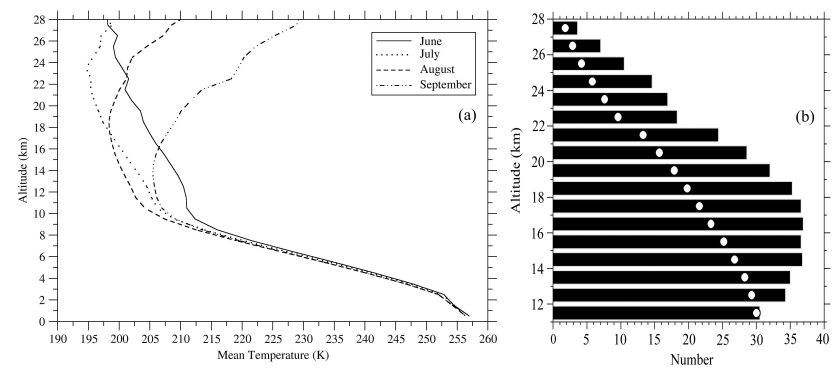

Fig. 8. (a) Monthly mean temperature profiles, for June to September, for the 1979-2008 period and (b) occurrence of $T<T_{\text {NAT }}$ events according to the altitude for the June to September period, between 1989 and 2008; white circles indicate the number of soundings.

is clearly much smaller in the troposphere compared to the $\sim 40 \mathrm{~K}$ amplitude changes in the $15-25 \mathrm{~km}$ altitude range. During the summer months (Dec-Jan-Feb), the lowest temperatures are observed at $10 \mathrm{~km}$, which is approximately the mean tropopause altitude for this polar location. The lowest mean temperatures are observed at $20-25 \mathrm{~km}$ in the winter in July, after a continuous cooling starting approximately in February. The stratosphere cools from the top to the bottom. Temperature reaches its minimum earlier at high altitudes than at lower levels by about one month. The coldest temperatures occur in July at $25 \mathrm{~km}$, and then in August in the lowermost stratosphere $(15 \mathrm{~km})$. The rate of temperature decrease is also greater at higher altitudes. The mid-stratosphere $(25 \mathrm{~km})$ begins to cool at a rate exceeding $10 \mathrm{~K} /$ month, starting at the end of January, whereas the rate is only $\sim 5 \mathrm{~K} /$ month at $15 \mathrm{~km}$, starting in March. From roughly mid-June to beginning of September, mean stratospheric temperatures drop to values close or below the temperature threshold for Nitric Acid Trihydrate (NAT), as calculated with the Hanson and Mauersberger (1988) formulae (for $10 \mathrm{ppbv} \mathrm{HNO}_{3}$ and $5 \mathrm{ppmv} \mathrm{H}_{2} \mathrm{O}$ ). The rate of the springtime temperature increase is greater than the autumn cooling rate, reaching almost $20 \mathrm{~K} / \mathrm{month}$ at $25 \mathrm{~km}$ in September. Our stratospheric temperature climatology over Dumont d'Urville is consistent with previous findings at this location (David et al., 1998) and presents features that are similar to climatologies at McMurdo and South Pole stations (Trenberth and Olson, 1989). This again underlines a homogeneous behavior of the Antarctic vortex with respect to temperature, from inner regions to the edge.

Temperatures in the stratosphere during winter show a large variability, especially on the edge of the vortex. As PSC formation is a threshold process, mean seasonal temperature is thus not the only pertinent parameter for investigating PSC formation conditions. The temperature fluctuations and the minimums have also to be considered. The key parameter for PSCs is the temperature events below $T_{\mathrm{NAT}}$, because the NAT formation temperature is expected to be the 
maximum temperature at which PSCs can exist (Lowe and MacKenzie, 2008 and references therein). The critical temperature threshold, $T_{\mathrm{NAT}}$, depends on the $\mathrm{HNO}_{3}$ and $\mathrm{H}_{2} \mathrm{O}$ stratospheric contents and on altitude. The 1979-2008 mean temperature profiles for the June to September period, the period of PSC detection, are shown on Fig. 8a. The polar tropopause height is located between 8 and $12 \mathrm{~km}$ and varies all through the year. The altitude distribution of $T<T_{\mathrm{NAT}}$ events occurrence is displayed on Fig. 8b, together with the mean number of temperature soundings available per month at each altitude level. For the calculations of $T_{\mathrm{NAT}}$, typical $\mathrm{HNO}_{3}$ and $\mathrm{H}_{2} \mathrm{O}$ levels are used (10 ppbv $\mathrm{HNO}_{3}$ and 5 ppmv $\mathrm{H}_{2} \mathrm{O}$ ). The fixed water vapour and nitric acid vapour content used for the calculations may not always be representative of the real available amounts, especially at the end of the winter after stratospheric air has been processed by denitrification and possible dehydration. The percentage of days with $T<T_{\mathrm{NAT}}$ (e.g. the number of soundings with temperature lower than $T_{\mathrm{NAT}}$ divided by the total number of soundings) is calculated for the June-September period, at each altitude level. From the available temperature profiles, it appears clearly that the $T<T_{\mathrm{NAT}}$ events occur mainly in the 12 $23 \mathrm{~km}$ altitude range with a mean frequency between 25 and $37 \%$. The maximum occurrence is observed between 14 and $18 \mathrm{~km}$ over the 1979-2008 period. As expected, the peak of $T<T_{\mathrm{NAT}}$ occurrences frequency roughly corresponds to the temperature minimum. The occurrence frequency is difficult to estimate reliably at higher levels, because the number of measurements decreases rapidly above $22-23 \mathrm{~km}$ as most balloons burst around this altitude level. As Dumont d'Urville is located outside the vortex in about $5 \%$ of the cases during winter (Godin et al., 2001), the position of the station with respect to the vortex position is not likely to lead to a significant underestimation of the $T<T_{\mathrm{NAT}}$ events frequency.

\subsection{PSC and $T<T_{\mathrm{NAT}}$ evolutions}

In this section, we compare the time evolution of PSC occurrences, as observed with the aerosol lidar in DDU with the time evolution of $T<T_{\mathrm{NAT}}$ events occurrences, derived from radiosonde data.

Aerosol lidar measurements are performed at Dumont d'Urville since 1989 (David et al., 1998) providing the only continuous aerosol lidar measurements over 20 years in Antarctica. This unique database on PSC allows making the first analysis of a potential direct link between minimum stratospheric temperature trends and PSC occurrence trends, based on observations. The lidar system was renewed in 2005, but without noticeable changes. A laser failure prevented observations in 2000 and only test measurements were made in 2005. Except for these two years, PSCs measurements have been carried out every year, from roughly mid-June to beginning of September (David et al., 1998; Santacesaria et al., 2001). Figure 9a displays the num- ber of lidar measurements per year, for the June to September period, from 1989 to 2008, together with the number of PSCs detections. As lidar can only operate in clear sky conditions, the measurement frequency varies a lot from one year to another, because of the inter-annual variability in tropospheric cloud cover. The proportion of PSCs detection (e.g. number of PSCs detected over the number of measurement days) is not constant from one year to another, mostly because PSC periods are not sampled regularly from one year to another. The evolution of the percentage of PSCs detections (at any altitude) and of the $T<T_{\mathrm{NAT}}$ occurrence (\%) for the corresponding lidar measurement days (thereafter referred as measurement $T<T_{\mathrm{NAT}}$ occurrence) are plotted in figure $9 \mathrm{~b}$ from 1989 to 2008 . Figure $9 \mathrm{c}$ represents the occurrence of $T<T_{\mathrm{NAT}}$ days over the 120 days from 1 June to 30 September (thereafter referred as absolute $T<T_{\text {NAT }}$ occurrence), independently from lidar measurements, for each year between 1989 and 2008. The sample used for calculating the absolute $T<T_{\mathrm{NAT}}$ occurrence is much bigger than the sample of the measurement $T<T_{\mathrm{NAT}}$ occurrence that only consider the days of the lidar measurements.

As expected, the measurement derived PSC occurrence is extremely well correlated with the measurement $T<T_{\mathrm{NAT}}$ occurrence. The number of detected PSCs is almost always lower than the number of days with $T<T_{\mathrm{NAT}}$, except in 1992 and 1993. The high number of PSCs detected in 1992, while the number of absolute $T<T_{\mathrm{NAT}}$ occurrence is low, can be directly related to the highly enhanced aerosols loading the year after the joint Mt Pinatubo and Cerro Hudson eruptions (respectively in June and August 1991). During the two years following the eruptions, 1992 and 1993, the presence of dense volcanic particles layers in the lower stratosphere made difficult the discrimination between Type Ib PSCs and volcanic aerosols. The algorithm used to detect PSCs from the monthly average scattering ratio profiles may artificially increase the PSC counting (David et al., 1998). Even if volcanic clouds may enhance the potential of PSC formation by providing additional support material, the number of PSCs during those post-eruptions years is probably over-estimated by our algorithm (David et al., 1998). In 2002, the effect of the unusually early sudden major stratospheric warming (Newman et al., 2005; Simmons et al., 2005; Stolarski et al., 2005) clearly appears with low numbers of both $T<T_{\mathrm{NAT}}$ events (as recorded by measurement and absolute $T<T_{\mathrm{NAT}}$ occurrences) and PSC detections. The minimum in measurement $T<T_{\mathrm{NAT}}$ occurrence in 1994 indicates that the sampling was biased towards the warm events during that year because the absolute $T<T_{\mathrm{NAT}}$ occurrence during that winter was not an extreme (see Fig. 9c).

The fact that the number of detected PSCs is almost always lower than the number of days with $T<T_{\mathrm{NAT}}$ may also suggest that crossing down the NAT threshold is not enough to trigger PSC formation and, hence, not the most accurate criteria for the onset of chlorine activation in global-scale models. Drdla and Schoeberl (2003) already mentioned, on a 

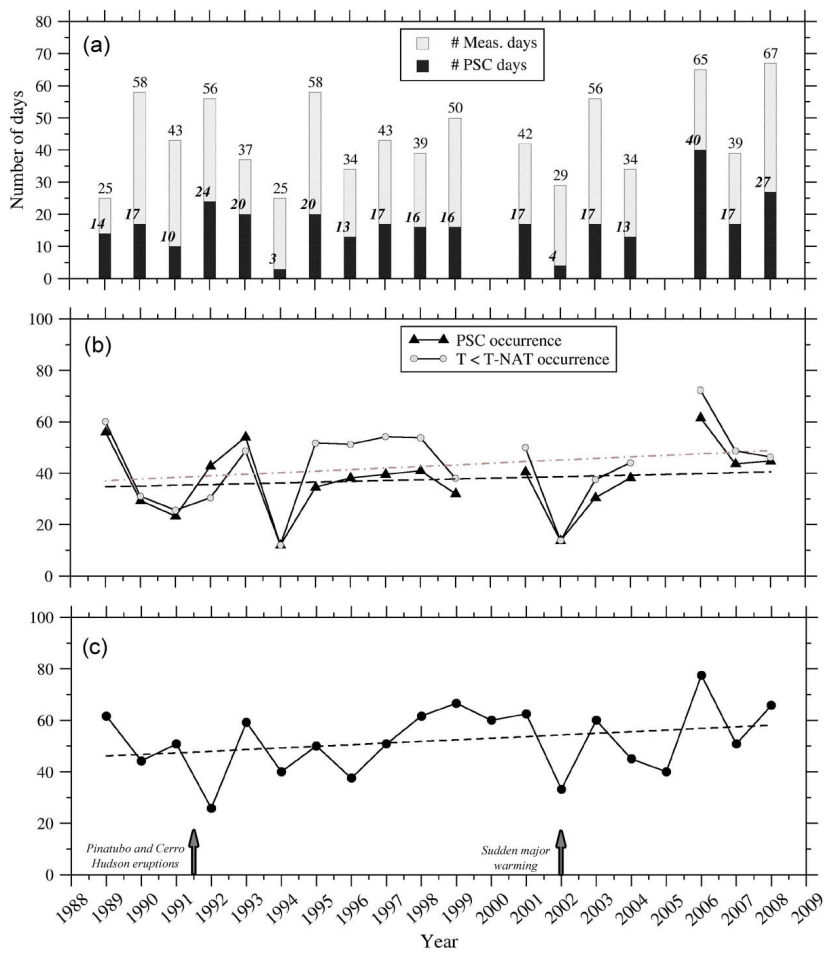

Fig. 9. Between 1989 and 2008 at Dumont d'Urville, (a) number of lidar measurements per year for the June to September period together with the number of PSCs detections per year for the same period, (b) occurrences (\%) of $T<T_{\mathrm{NAT}}$ events (grey circles) and PSC (black triangle) over the number of lidar observations days, and (c) absolute occurrence ( $\%$ ) of $T<T_{\text {NAT }}$ days over the 120 days from 1 June to 30 September (independently of lidar measurements). Note that the PSC and $T<T_{\text {NAT }}$ occurrences are considered between the tropopause plus $1 \mathrm{~km}$ and $28 \mathrm{~km}$.

diagram of temporal evolution of the vertical extend, that the region of $\mathrm{HCl}$ activation due to heterogeneous reactions is much smaller than the region of NAT particles possible existence (see also http://geo.arc.nasa.gov/sgg/res_proj_1pagers/ Polar_O3_loss.pdf). More recently, Pitts et al. (2007) compared the volumetric extend of NAT threshold $\left(V_{\mathrm{TNAT}}\right)$ calculated with MLS $\mathrm{HNO}_{3}$ vapour contents to the volumetric extend of PSC ( $V_{\mathrm{PSC}}$ ) as seen by CALIPSO and find out a highly non-linear relationship between $V_{\mathrm{PSC}}$ and $V_{\mathrm{TNAT}}$, where $V_{\text {TNAT }}$ significantly overestimates $V_{\text {PSC. }}$. They also show that the relationship remains quite consistent from year to year and is consistent between the two polar regions as well.

The probability of absolute $T<T_{\mathrm{NAT}}$ occurrences is very variable from year to year (see fig. 9c). There are two clear minimums. The first one, in 1992, may be related to the Pinatubo eruption and its volcanic aerosols that have been shown to warm the stratosphere (ASAP, 2006; Robock et al., 2000), explaining the low number of $T<T_{\mathrm{NAT}}$ days this year. The other minimum in 2002 is related to the ex- ceptionally early stratospheric warming. The maximum in 2006 reflects the particularly cold Antarctic winter of that year. There seems to be a positive long term trend in the absolute $T<T_{\mathrm{NAT}}$ occurrence of $+6.3 \pm 4.9 \% /$ decade over Dumont d'Urville which is statistically significant to $1 \sigma$. Since there are no trends in the mean temperature over DDU during winter (see Fig. 5), this apparent trend is likely to indicate a long-term change in the frequency of temperatures extremes during winter over the considered period. The measurement $T<T_{\text {NAT }}$ occurrence (over the lidar observations days) exhibits a similar trend of $+6.1 \pm 6.3 \% /$ decade which is of the same order of magnitude than the absolute $T<T_{\text {NAT }}$ occurrence, but is not statistically significant. The higher variability in measurement $T<T_{\mathrm{NAT}}$ occurrence originates from the noise introduced by the smaller sample of simultaneous measurements of PSC and temperature.

The trend in PSCs occurrence frequency, drawn out from lidar observations in Dumont d'Urville over the last 20 years, is positive $(+3.2 \pm 5.4 \% /$ decade $)$, but clearly not statistically significant. The lidar PSCs detection is well correlated to the absolute $T<T_{\mathrm{NAT}}$ occurrence which exhibits a statistically significant positive trend. The inter-annual variability in PSCs occurrences is rather high over DDU. In addition, during the Antarctic winter, the favourable weather conditions for lidar operations can be all together very rare and not evenly distributed over the season. Our statistics of PSCs detections are distorted by the measurement sampling. A PSC can exist and not be detected because measurements are not possible at that time; at the same time, false PSC detections are highly unlikely. As a result, PSCs occurrence frequency is certainly underestimated. This PSC under-detection can be expected to be randomly distributed over the 20 years of observations. It is unlikely that the distortion due to lidar sampling could mask or reverse a real trend in PSCs. Therefore, even if not statistically significant, the positive longterm trend in PSCs occurrence frequency above DDU, in the edge region of the Antarctic vortex, is probably a real feature, which is consistent with the observed positive trend in $T<T_{\text {NAT }}$ temperature events. This apparent increase in PSCs occurrence above DDU should be further explored at other Antarctic measurement sites.

\section{Conclusions}

Temperature profiles measurements are performed daily (00:00 UT) in Dumont d'Urville by Météo-France, using standard radiosondes since the International Geophysical Year in 1957, with a gap of 16 years. Only low resolution temperature data from 1979 to present were used in previous studies. High resolution data prior to 1989 were made available recently by Météo-France. Although the data are still incomplete, the present paper aimed to investigate whether the stratospheric cooling trends observed at the other Antarctic stations and predicted by models are also detectable and 
are of the same order of magnitude in the Dumont d'Urville time series, which have never been studied independently before.

We found a temperature drop of about $11.3 \mathrm{~K}$ (that is, a cooling of about $2.3 \mathrm{~K} / \mathrm{decade}$ ) at $20 \mathrm{~km}$ between 1957 and 2008, consistent with other Antarctic studies (Thompson and Solomon, 2002; Randel et al., 2009). Over the last 50 years the stratosphere has cooled at the edge of the vortex, with amplitude somewhat similar to those observed in the inner vortex. Nonetheless, the 16 years data gap between 1963 and 1978 is too large to allow us to distinguish between potential instrumental changes and real atmospheric changes. Only the most recent series, between 1979 and 2008, is used to investigate the trend and inter-annual variability in stratospheric temperatures. Since 1992, independent complementary temperature series from ozone soundings are also available, allowing some checking of Météo-France temperature time series. The mean difference between both temperature time series increases with altitude to reach about $1 \mathrm{~K}$ at $15 \mathrm{~km}$ and $2 \mathrm{~K}$ at $25 \mathrm{~km}$, giving an idea about the accuracy of the radiosonde temperatures.

The picture drawn with observations in Dumont d'Urville should be representative of the edge of the vortex, where stratospheric temperatures never drop as low as within the inner vortex. In this edge region, the annual mean temperature cooling of about $1 \mathrm{~K} / \mathrm{decade}$ is the result of the cooling trends detected in summer and autumn and a warming trend in spring. During austral summer and autumn a significant cooling lying between 0.5 and $1.4 \mathrm{~K} /$ decade is derived. This cooling and the vertical trends above a station located at the edge of the vortex are consistent with trends estimated by Randel et al. (2009) using data from three inner vortex stations. The amplitude of the negative trend at DDU is smaller $(-0.8 \mathrm{~K} /$ decade for DDU at $15 \mathrm{~km}$ compared to $-1.3 \mathrm{~K} /$ decade in Randel et al.). In spring, a warming of about $+1.1 \mathrm{~K} /$ decade is derived but with a large error produced by the very large variability resulting from the sampling of different air masses, partly inside or at the edge of the vortex and partly outside. No statistically significant trend is detected in winter.

Climate changes strongly interact with ozone chemistry. Stratospheric cooling is a response to both GHG increase and ozone decrease (IPCC, 2007; WMO, 2007). As PSC form at low temperatures during winter, a cooling would boost their formation, which in turn, may negatively impact ozone. The unique continuous database of PSC lidar detection over 20 years allows correlating for the first time lidar PSC observations with measured minimum stratospheric temperatures. Despite the absence of trend in the mean temperature during winter, the occurrence of such cold events (temperatures below the NAT threshold) between 1989 and 2008 exhibit a significant trend of about $+6 \% /$ decade. The PSCs occurrences frequency derived from lidar data exhibits a concomitant trend of about $+3 \%$ /decade, although not statistically significant partly because of lidar operation constraints.
Similar features are found in the Arctic stratosphere where the inter-annual variability of winter temperatures is much more pronounced than in the Antarctic. From an analysis of a composition of ECMWF and FUB data over the past 40 years, the cold Arctic winters were shown to become colder, resulting in larger volumetric extend of PSC and subsequent chemical ozone loss (WMO, 2006; Rex et al., 2004). The increase occurrence of $T<T_{\mathrm{NAT}}$ temperatures during winter above DDU while the mean temperature does not exhibit a trend might be related to an increase in the amplitude of temperature fluctuations (e.g. cold events becoming colder). As already suggested, the change of temperature patterns during cold winters may be different from the overall mean temperature trend (WMO, 2006). The trends on extreme temperatures thus have to be considered, and not only the trends on mean temperatures.

More deeply into the vortex, temperatures already remained below the NAT threshold almost throughout the winter and even below the ice threshold during a long time period. Studies of stratospheric temperatures evolution have been carried out at the hemispheric scale (Ramaswamy et al., 2001; Randel and Wu, 1999; Randel et al., 2009; Thompson and Solomon, 2002, 2005). Regional scale analyses have been performed only for surface and mid-troposphere temperatures (Turner et al., 2005; Steig et al., 2009). It would be interesting to investigate further the stratospheric temperatures at these lower scales.

In particular, it would be interesting to explore whether the region of extremely cold temperatures (usually confined to the inner vortex) could extent and persist at the outer edge of the vortex, leading to an area covered by PSCs almost as large as the Antarctic continent throughout the austral winter. In these conditions, ice PSCs (Type II) could also become more frequent on the edge regions of the vortex. Such an evolution would certainly have an important impact on chlorine activation and ozone recovery and also on climate. Over the last 50 years, the mid-troposphere Antarctic temperatures have increased around the $500 \mathrm{hPa}$ level with statistically significant changes of $0.5-0.7 \mathrm{~K} /$ decade (Turner et al., 2006). Using an idealised model of ice PSC increases, Lachlan-Cope et al. (2009) showed that they could have contributed to the observed mid-troposphere warming.

Acknowledgements. Thanks to the three anonymous referees for helpful comments on the manuscript.

Radiosondes temperature data were provided by Météo-France. We are particularly grateful to Christian Lafayne, Gilbert Gayraud and Gérard Rey for their help in reconstructing this database. We also address a special thank to the Météo-France operators in Dumont d'Urville: Antoine Kergomard, Geneviève Caisso and Pierre Tixerand in 2006 and Régis Tellier, Denis Souverbie and Joseph Morretta in 2008.

The Dumont d'Urville station is a primary site of the NDACC and is managed by the IPSL "NDACC-France" Observing Service. The logistics and operations are funded and supported by the French 
Polar Institute "Paul-Emile-Victor" (IPEV). The authors wish to thanks all the involved members of IPEV for their constant implication and their never-failing efficiency.

The aerosol/PSC lidar in Dumont d'Urville is operated within a French-Italian collaboration between IPSL in Paris and ISAC-CNR in Roma.

Anthony Armetta established the temperature climatology over Dumont d'Urville during his Master degree at University Paris 6.

This work is part of the International Polar Year project ORACLEO3. It has been supported by the French Research National Agency (Agence National de la Recherche - ANR) under the current contract No. BLAN06-1_135745 (ORACLE-France) and by the Environment and Climate Research Programme of the European Commission under the completed contract No. GEOMON-036677. We acknowledge the support of the GEMS Integrated Project which is funded by the European Commission.

Edited by: D. Shindell

\section{References}

ASAP, Assessment on Stratospheric Aerosol Properties: WCRP124, WMO/TD-No. 1295, SPARC Report No. 4, 2006.

Austin, J., Wilson, R. J., Akiyoshi, H., Bekki, S., Butchart, N., Claud, C., Fomichev, V. I., Forster, P., Garcia, R. R., Gillett, N. P., Keckhut, P., Langematz, U., Manzini, E., Nagashima, T., Randel, W. J., Rozanov, E., Shibata, K., Shine, K. P., Struthers, H., Thompson, D. W. J., Wu, F., and Yoden, S.: Coupled chemistry climate model simulations of stratospheric temperatures and their trends for the recent past, Geophys. Res. Lett., 36, L13809, doi:10.1029/2009GL038462, 2009.

Beig, G., Keckhut, P., Lowe, R. P., Roble, R. G., Mlynczak, M. G., Scheer, J., Fomichev V. I., Offermann D., French W. J. R., Shepherd, M. G., Semenov, A. I., Remsberg, E. E., She, C. Y., Lübken, F. J., Bremer J., Clemesha, B. R., Stegman, J., Sigernes, F., and Fadnavis, S.: Review of mesospheric temperature trends, Rev. Geophys., 41(4), 1015, doi:10.1029/2002RG000121, 2003.

Butchart, N., Scaife, A. A., Bourqui M., de Grandpré, J., Hare, S. H. E., Kettleborough, J., Langematz, U., Manzoni, E., Sassy, F., Shibata, K., Shindell, D., and Sigmund, M.: Simulations of anthropogenic change in the strength of the Brewer-Dobson circulation, Clim. Dinam., 27, 727-741, 2006.

Cordero, E. C. and de Forster P. M.: Stratospheric variability and trends on models used for the IPCC AR4, Atmos. Chem. Phys., 6, 5369-5380, 2006,

http://www.atmos-chem-phys.net/6/5369/2006/.

Dameris, M., Grew, V., Ponater, M., Deckert, R., Eyring, V., Mager, F., Matthes, S., Schnadt, C., Stenke, A., Steil, B., Brühl, C., and Giorgetta, M. A.: Long-term changes and variability in a transient simulation with a chemistry-climate model employing realistic forcing, Atmos. Chem. Phys., 5, 2121-2145, 2005, http://www.atmos-chem-phys.net/5/2121/2005/.

David, C., Bekki, S., Godin, S., Mégie, G., and Chipperfield, M. P.: Polar Stratospheric Clouds climatology over Dumont d'Urville between 1989 and 1993 and the influence of volcanic aerosols on their formation, J. Geophys. Res., 103, 22163-22180, 1998.

Drdla, K. and M. R. Schoeberl, Microphysical modeling of the 1999-2000 Arctic winter 2. Chlorine activation and ozone deple- tion, J. Geophys. Res., 108, 8319, doi:10.1029/2001JD001159, 2003.

Engel, A., Mobius, T., Bonisch, H., Schmidt, U., Heinz, R., Levin, I., Atlas, E., Aoki, S., Nakazawa, T., Sugawara, S., Moore, F., Hurst, D., Elkins, J., Schauffler, S., Andrews, A., and Boering, K.: Age of stratospheric air unchanged within uncertainties over the past 30 years, Nat. Geosci., 2, 28-31, 2009.

Forster, P. and Shine K. P.: Radiative forcing and temperature trends from stratospheric ozone changes, J. Geophys. Res., 102, 10,841-10,855, 1997.

Gaffen, D. J., Sargent, M. A., Habermann, R. E., and Lanzante, J. R.: Sensitivity of tropospheric and stratospheric temperature trends to radiosonde data quality, J. Clim., 13, 1776-1796, 2000.

Godin, S., Bergeret, V., Bekki, S., David, C., and Mégie, G.: Study of the interannual ozone loss and the permeability of the Antarctic polar vortex from aerosol and ozone lidar measurements in Dumont d'Urville $\left(66,4^{\circ} \mathrm{S}, 140^{\circ} \mathrm{E}\right)$, J. Geophys. Res., 106, 1311-1330, 2001.

Hansen, J., Lacis, A., Ruedy, R., and Sato, M.: Potential climate impact of Mount Pinatubo eruption, Geophys. Res. Lett., 19(2), 215-218, 1992.

Hanson, D. R. and Mauersberger, K.: Laboratory studies of the nitric acid trihydrate: Implications for the South Polar Stratosphere, Geophys. Res. Lett., 15, 855-858, 1988.

Hauchecorne, A., Chanin, M. L., and Keckhut, P.: Climatology and trends of the middle atmospheric temperature $(33-87 \mathrm{~km})$ as seen by Rayleigh lidar over the south of France, J. Geophys. Res., 96, 15297-15309, 1991.

IPCC: Climate Change 2007: Synthesis Report. Contribution of Working Groups I, II and III to the Fourth Assessment Report of the Intergovernmental Panel on Climate Change [Core Writing Team, edited by: Pachauri, R. K. and Reisinger, A., IPCC, Geneva, Switzerland, 104 pp., 2007.

Jiang, X., Eichelberger, S. J., Hartmann, D. L., Shia, R., and Yuan, Y. L.: Influence of doubled $\mathrm{CO}_{2}$ on ozone via changes in the Brewer-Dobson circulation, J. Atmos. Sci., 64, 2751-2755, 2007.

Keckhut, P., Hauchecorne, A., and Chanin, M. L.: Mid-latitude long-term variability of the middle atmosphere trends, and cyclic and episodic changes, J. Geophys. Res., 100, 18887-18897, 1995.

Keckhut, P., Schmidlin, F. J., Hauchecorne, A., and Chanin, M. L.: Stratospheric and mesospheric cooling trend estimates from us rocketsondes at low latitude stations $\left(8^{\circ} \mathrm{S}-34^{\circ} \mathrm{N}\right)$, taking into account instrumental changes and natural variability, J. Atmos. Sol. Terr. Phys., 61, 447-459, 1999.

Kerzenmacher, T. E., Keckhut, P., Hauchecorne, A., and Chanin, M. L.: Methodological uncertainties in multi-regression analyses of middle-atmospheric data series, J. Environ. Monit., 8, 682-690, doi:10.1039/b603750j, 2006.

Kurylo, M. J. and Solomon, S.: Network for the Detection of Stratospheric Change: a status and implementation report, NASA Upper Atmosphere Research Program and NOAA Climate and Global Change Program (NASA), Washington DC, USA, 1990.

Labitzke, K. and McCormick, M. P.: Stratospheric temperature increases due to Pinatubo aerosols, Geophys. Res. Lett., 19, 207210, 1992.

Lachlan-Cope, T. A., Connolley, W. M., Turner, J., Roscoe, H., Marshall, G. J., Colwell, S. R., Höpfner, M., and Ingram, W.: 
Antarctic winter tropospheric warming - the potential role of polar stratospheric clouds, a sensitivity study, Atmos. Sci. Lett., 10, 262-266, doi:10.1002/asl.238, 2009.

Langematz, U., Kunze, M., Krüger, K., Labitzke, K., and Roff, G. L.: Thermal and dynamical changes of the stratosphere since 1979 and their link to ozone and $\mathrm{CO}_{2}$ changes, J. Geophys. Res., 108, 4027, doi:10.1029/2002JD002069, 2003.

Li, F., Austin, J., and Wilson, J.: The strength of the BrewerDobson circulation in a changing climate: Coupled chemistryclimate model simulations, J. Climate, 21, 40-57, 2008.

Li, F., Stolarski R. S., and Newman, P. A.: Stratospheric ozone in the post-CFC era, Atmos. Chem. Phys., 9, 2207-2213, 2009.

Logan, J. A.: Trends in the vertical distribution of ozone: An analysis of ozonesonde data, J. Geophys. Res., 99(D12), 2555325586, 1994.

Lowe, D. and MacKenzie, A. R.: Polar stratospheric cloud microphysics and chemistry, J. Atmos. Sol.-Terr. Phy., 70, 13-40, 2008.

Mayewski, P.A., Meredith M.P., Summerhayes C.P., Turner J., Worby A., Barrett P.J., Casassa G., Bertler N.A.N., Bracegirdle T., Naveira Garabato A.C., Bromwich D., Campbell H., Hamilton G.S., Lyons W.B., Maasch K.A., Aoki S., Xiao C., and van Ommen T.: State of the Antarctic and Southern Ocean climate system, Rev. Geophys., 47, RG1003, doi:10.1029/2007RG000231, 2009.

Newman, P. A, Nash E. R.: The Unusual Southern Hemisphere Stratosphere Winter of 2002, J. Atmosph. Sci., 62, 3, 614-628, 2005.

Parker, D. E., and Cox D. I.: Toward a consistent global climatological rawinsonde data base, Int. J. Climatology, 15, 473-496, 1995.

Peter, T.: Microphysics and heterogeneous chemistry of polar stratospheric clouds, Ann. Rev. Phys. Chem., 48, 779-816, 1997.

Pitts, M. C., Thomason, L. W., Poole, L. R., and Winker, D. M.: Characterization of polar stratospheric clouds with spaceborne lidar: CALIPSO and the 2006 Antarctic season, Atmos. Chem. Phys., 7, 5207-5228, 2007,

http://www.atmos-chem-phys.net/7/5207/2007/.

Ramaswamy, V., Chanin, M. L., Angell, J., Barnett, J., Gaffen, D., Gelman, M., Keckhut, P., Koshelkov, Y., Labitzke, K., Lin, R., O’Neill, A., Nash, J., Randel, W., Rood, R., Shine, K., Shiotani, M. and Swinbank, R.: Stratospheric temperature trends: observations and model simulations, Rev. Geophys., 39, 71-122, 2001.

Ramaswamy, V. and Schwarzkopf, M. D.: Effects of ozone and well-mixed gases on annual-mean stratospheric temperature trends, Geophys. Res. Lett., 29, 2064, doi:10.1029/2002GL015141, 2002.

Ramaswamy, V., Schwarzkopf M. D., Randel W. J., Santer B. D., Soden B. J., and Stenchikov, G. L.: Anthropogenic and natural influences in the evolution of lower stratospheric cooling, Science, 311, 1138-1141, 2006.

Randel, W. J. and Wu, F.: Cooling of the Arctic and Antarctic polar stratospheres due to ozone depletion, J. Climate, 12, 1467-1479, 1999.

Randel, W.J, Shine, K. P., Austin, J., Barnett, J., Claud, C., Gillett, N. P., Keckhut, P., Langematz, U., Lin, R., Long, C., Mears, C., Miller, A., Nash, J., Seidel, D. J., Thompson, D. W. J., Wu F., and Yoden, S.: An update of observed stratospheric temperature trends, J. Geopys. Res., 114, D02107,
doi:10.1029/2008JD010421, 2009.

Rex, M., Salawitch, R. J., von der Gathen, P., Harris, N. R. P., Chipperfield, M. P., and Naujokat, B.: Arctic ozone loss and climate change, Geophys. Res. Lett., 31, L04116, doi:10.1029/2003GL018844, 2004.

Rind, D., Suozzo, R., Balanchandra, N. K. and Prather, M. J.: Climate change and the middle atmosphere. Part I: The doubled $\mathrm{CO}_{2}$ climate, J. Atmos. Sci., 47, 475-494, 1990.

Rind, D., Blachandran, N. K., and Suozzo, R.: Climate change and the Middle Atmosphere. Part II: The impact of Volcanic aerosols, J. Climate, 5, 189-208, 1992.

Robock, A.: Volcanic eruptions and climate, Rev. Geophys., 38, 191-219, 2000.

Robock, A., Adams, T., Moore, M., Oman, L., and Stenchikov, G.: Southern Hemisphere atmospheric circulation effects of the 1991 Mount Pinatubo eruption, Geophys. Res. Lett., 34, L23710, doi:10.1029/2007GL031403, 2007.

Rosier, S. M. and Shine K. P.: The effect of two decades of ozone change on stratospheric temperature, as indicated by a general circulation model, Geophys. Res. Lett., 27, 2617-2620, 2000.

Santacesaria, V., MacKenzie, A. R., and Stefanutti, L.: A climatological study of polar stratospheric clouds (1989-1997) from lidar measurements over Dumont d'Urville (Antarctica), Tellus (B), 53, 306-321, 2001.

Sato, M., Hansen, J. E., McCormick, M. P. and Pollack, J. B.: Stratospheric aerosol optical depth, 1850-1990, J. Geophys. Res., 98, 22987-22994, 1993.

Shepherd, T. G.: Dynamics, stratospheric ozone, and climate change, Atmos.-Ocean, 46, 117-138, 2008.

Shindell, D. T., and Schmidt, G. A.: Southern hemisphere climate response to ozone changes and greenhouse gas increase, Geophys. Res. Lett., 31, L18209, doi :101029/2004GL020724, 2004.

Shine, K.P., Bourqui M.S. , de F. Forster P.M., Hare S.H.E., Langematz U., Braesicke P., Grewe V., Ponater M., Schnadt C., Smith C.A., Haigh J.D., Austin J., Butchart N., Shindell D.T., Randel W.J., Nagashima T., Portmann R.W., Solomon S., Seidel D.J., Lanzante J., Klein S., Ramaswamy V., and Schwarzkopf M.D.: A comparison of model-simulated trends in stratospheric temperatures, Q. J. Roy. Meteorol. Soc., 129, 1565-1588, DOI: 10.1256/qj.02.186, 2003.

Simmons, A., Hortal, M., Kelly, G., McNally, A., Untch, A., and Uppala, S.: ECMWF Analyses and Forecasts of Stratospheric Winter Polar Vortex Breakup: September 2002 in the Southern Hemisphere and Related Events, J. Atmosph. Sci., 62, 3, 668689, 2005.

Solomon, S.: Stratospheric ozone depletion: A review of concepts and history, Rev. Geophys., 37, 275-316, 1999.

Steig, E. J., Schneider, D. P., Rutherford, S. D., Mann, M. E., Comiso, J. C., and Shindell, D. T.: Warming of the Antarctic ice-sheet surface since the 1957 International Geophysical Year, Nature, 457, 459-463, 2009.

Stolarski, R. S., McPeters, R. D., and Newman, P. A.: The Ozone Hole of 2002 as Measured by TOMS, J. Atmosph. Sci., 62, 3, 716-720, 2005.

Tiao, G. C., Xu, D., Pedrick, J. H., Zhu, X., and Reinsel, G. C.: Effect of autocorrelation and temporal schemes on estimates of trend and spatial correlation, J. Geophys. Res., 95, 20507-20517, 1990.

Tiefenau, H. K. E. and Gebbeken, A.: Influence of meteorological 
balloons on temperature measurements with radiosondes: nighttime cooling and daylight heating, J. Atmos. Oceanic Tech., 6, 36-42, 1989.

Thompson, D. W. J. and Solomon, S.: Interpretation of recent southern hemisphere climate change, Science, 296, 895-899, 2002.

Thompson, D. W. J. and Solomon, S.: Recent Stratospheric Climate Trends as Evidenced in Radiosonde Data: Global Structure and Tropospheric Linkages, J. Climate, 18, 4785-4795, 2005.

Thompson, D. W. J. and Solomon, S.: Understanding Recent Stratospheric Climate Change, J. Climate, 22, 1934-1943, 2009.

Trenberth, K. E. and Olson J. G.: Temperature trends at the South Pole and McMurdo Sound, J. Clim., 2, 1196-1206, 1989.

Turner, J., Lachlan-Cope, T. A., Colwell, S., Marshall, G. J., and Connolley, W. M.: Significant Warming of the Antarctic Winter Troposphere, Science, 311, 1914-1917, 2006.
Turner, J., Colwell, S. R., Marshall, G. J., Lachlan-Cope, T. A., Carleton, A. M., Jones, P. D., Lagun, V., Reid, P. A., and Iagovkinaf, S.: Antarctic climate change during the last 50 years, Int. J. Climatol., 25, 279-294, 2005.

Waugh, D. W., Randel, W. J., Pawson, S., Newman, P. A., and Nash, E. R.: Persistence of the lower stratospheric polar vortices, J. Geophys. Res., 104(D22), 27191-27201, 1999.

WMO (World Meteorological Organization), Scientific Assessment of Ozone Depletion: 1994, Global Ozone Research and Monitoring Project, Report No. 37, 584 pp., Geneva, Switzerland, 1995.

WMO (World Meteorological Organization), Scientific Assessment of Ozone Depletion: 2006, Global Ozone Research and Monitoring Project, Report No. 50, 572 pp., Geneva, Switzerland, 2007. 